\title{
Urban transformation with TURAS open innovations; opportunities for transitioning through transdisciplinarity
}

Marcus J Collier ${ }^{1}$, Stuart Connop ${ }^{2}$, Karen Foley ${ }^{3}$, Zorica Nedović-Budić ${ }^{3}$, Darryl Newport ${ }^{2}$, Aoife Corcoran ${ }^{3}$, Philip Crowe ${ }^{3}$, Louise Dunne ${ }^{3}$, Hans de Moel ${ }^{4}$, Stephan Kampelmann ${ }^{5}$, Siobhán McQuaid ${ }^{6}$, Hans-Georg Schwarz von Raumer ${ }^{5}$, Aleksander Slaev ${ }^{7}$, Eva-Maria Stumpp ${ }^{5}$, Patrick Van den Abeele $^{8}$ and Paula Vandergert ${ }^{2}$

Transitioning is a unidirectional process of mainstreaming sustainability within normative societal behaviour, which communities hope will build resilience, reduce our dependence on distant resources and lead to the transformation towards more sustainable living as an end product. Throughout Europe there are numerous examples and pilot or demonstration projects that illustrate tools, practices, mechanisms, pathways and policies for how transitioning can be guided and a transformation can be achieved. This paper draws on the experience of the TURAS project by illustrating some of the diverse open innovation opportunities that have been derived using novel transdisciplinary approaches. The paper concludes with identifying possible ways forward by utilising the TURAS innovations to enable the transformation of urban communities.

\footnotetext{
Addresses

${ }^{1}$ School of Natural Sciences, Trinity College, Dublin, Ireland

${ }^{2}$ Sustainability Research Institute (SRI), University of East London, Docklands Campus, 4-6 University Way, London E16 2RD, UK

${ }^{3}$ UCD School of Architecture, Planning and Environmental Policy, University College Dublin, Belfield, Dublin 4, Ireland

${ }^{4}$ Institute for Environmental Studies (IVM), Vrije Universiteit Amsterdam, De Boelelaan, Amsterdam, The Netherlands

${ }^{5}$ University of Stuttgart, Faculty of Architecture and Urban Planning ILPOE Institute for Landscape Planning and Ecology, Keplerstr. 11, 70174 Stuttgart, Germany

${ }^{6}$ TCD School of Business and Innovation, Trinity College Dublin, College Green, Dublin 2, Ireland

${ }^{7}$ Varna Free University, Varna, Bulgaria

${ }^{8}$ Bruxelles Environnement/Brussel Leefmilieu, Avenue du Port 86c, Havenlaan, B-1000 Brussels, Belgium
}

Corresponding author: Collier, Marcus J (marcus.collier@tcd.ie)
Current Opinion in Environmental Sustainability 2017, 22:57-62

This review comes from a themed issue on System dynamics and sustainability

Edited by Niki Frantzeskaki, Dagmar Haase, Michail Fragkias and Thomas Elmqvist

Received: 19 May 2016; Revised: 26 February 2017;

Accepted: 11 April 2017

http://dx.doi.org/10.1016/j.cosust.2017.04.005

1877-3435/৫ 2017 Elsevier B.V. All rights reserved.

\section{Introduction}

Cities are the locus of the most significant of current and future global societal challenges. Urban 'communities of interest' are continually striving towards acquiring practical solutions to address these complex and dynamic socio-environmental issues with the ultimate goal of transforming how we live as an urban species. Understanding and facilitating this has seen the emergence of transdisciplinary research and demonstration projects. Transdisciplinarity involves the collaborative production (co-production) of knowledge and the collaborative creation (co-creation) of ideas and solutions $\left[1^{\circ}\right]$, a complex methodology which is especially suited to urban settings, where communities-of-interest are continually seeking active engagement in decision-making and positive control in city-making [2]. Transdisciplinarity is an approach that draws on the strengths of different disciplines (academics and non-academics) to address a complex issue [3]. Cities are ideal fora for transdisciplinarity, particularly in engaging diverse knowledge-holders $\left[4,5^{\circ}\right]$. However, realising transdisciplinary aims and objectives has been slow, and currently cities can vary greatly in the process, 
scale and scope of co-creation of knowledge and codesign of solutions. Indeed, many funders and supporters for transitioning processes that draw upon the co-creation of ideas often desire that outcomes result in a series of innovations that can both enable cohesion in urban living but also derive additional benefits and even value for money spent; something that is theoretically ideal but practically complex. This approach was tested in practice by the TURAS (Transitioning towards Urban Resilience and Sustainability) project. TURAS was devised to examine the implications of social-ecological resilience thinking on urban planning and policy and developing transdisciplinary strategies for transitioning. TURAS devised a unique perspective that was co-developed between academic institutions, local and municipal governments, and small or medium enterprises (SMEs). Recently, the
European Commission proposed an Open Innovation 2.0 paradigm $\left[6^{\circ}\right]$ based on a similar approach to TURAS where government, industry, academia and civil participants co-create solutions and drive structural changes beyond the scope of what any one organization or person may accomplish unassisted. This approach encompasses user-oriented innovation models to take full advantage of ideas' cross-fertilization leading to experimentation and prototyping in real world setting. Open innovation and cocreation processes frequently include differing 'holders' as co-creators and many open innovation environments aim to facilitate this interaction between companies and users [7]. For a more comprehensive discussion on the kinds of '-holders' in a governance setting, see [8], but different 'holders' (such as knowledge-holders, shareholders, right-holders, etc.) have diverse opinions on

\section{Figure 1}

\section{Communuties Directory \\ Community Geo-Timeline \\ EcoMimicry \\ Flood Damage Assesment \\ Go-Green \\ Pitching Green Infrastructure \\ Public Opinion on Transport \\ Revitalising Spaces \\ Sprawl Monitor \\ Sub-urban Ecosystem Payments, Fiscal Zoning \& Infrastructure Payments}

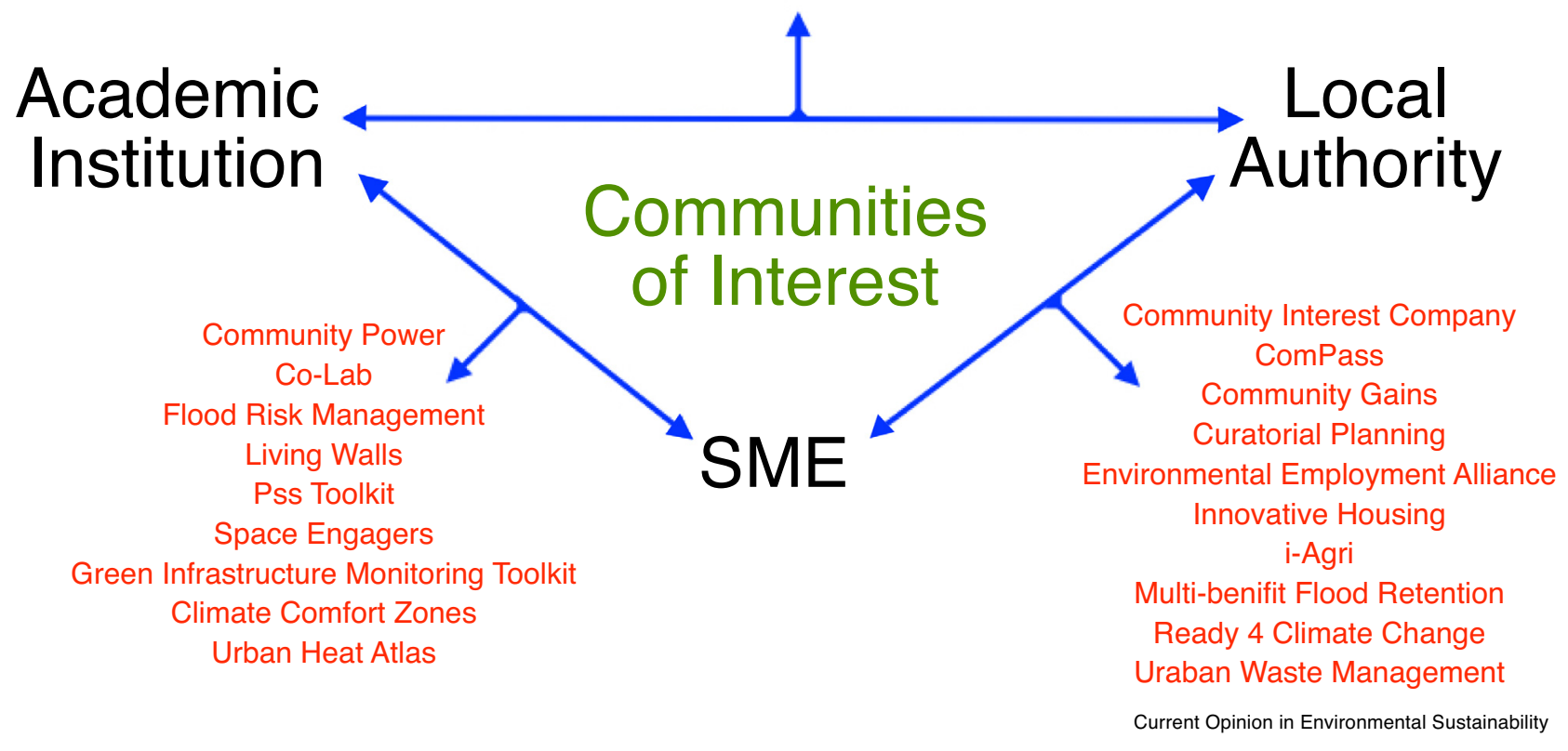

This is an illustration of the range, scope and variety of open-innovation that can arise from collaborative approaches between differing urbanfocused institutions. In each of the institutional pairings, urban communities of interest are essential consultative participants as well as net beneficiaries. The titles of the various innovations (in red) were primarily derived using a pair-wise approach, but in reality all four communities of interest (academia, municipalities, SMEs, and community stakeholders) were involved in collaborating on designing each of the innovations. These innovations are merely used as illustrative examples, and because space is limited, much more detail on each innovation can be seen here. However, for illustration some have been selected and expanded upon in Table 1. 
Table 1

Selected examples of differing innovations/solutions derived from the TURAS process. Here, the innovations are separated out for clarity of range, but in practice all of them contain topics that would cross between innovations

Innovative solution example (including link) for building resilience

Social innovation

Incremental innovation

Sustainability innovation

Knowledge innovation

Business innovation

Governance innovation

Open-source innovation
The Community Interest Company (CIC) solution. This is a co-developed social enterprise, where urban community assets are held and managed to invest in cohesion and enterprising activities, as well as the infrastructure required by local businesses and communities [27]. SMEs and local authorities engage with communities of interest to, for example, engage interested residents in managing and maintaining local green spaces, which could lead to activities such as local ecology and wildlife projects to enhance gardens and green spaces for amenity and for ecosystem services, helping to build local resilience, for example to flooding. Another example involves providing opportunities to identify suitable community land for local people who are interested in food growing, such as the creation of community gardens and orchards that can grow local fresh produce for sale or for processing into products for sale. Further ideas exist, such as providing local assets such as community centres that could be used for social clubs and for harnessing and developing local skills and enterprise, leading to job opportunities

The Flood Risk Management solution. Going beyond traditional modelling this innovation combines qualitative and quantitative methods to co-create strategies for short-, medium- and long-term adaptation [28]. Over decades, a great deal of modelling and other expertise and knowledge on flood risk has been accumulating. This innovation is an attempt to combine such knowledge with collaborative processes to ensure the long-term viability of building flood resilience

The Ecomimicry solution. This nature-based solution incorporates multiple ecosystem service delivery, centred around a locally contextualised habitat services approach, into the co-design of urban green infrastructure. It is universally applicable, and has been demonstrated on brownfield developments where the mosaic of low nutrient habitats can have exceptionally high biodiversity value and can represent regionally important habitats.

Ecomimicry of key habitat niches associated with brownfield sites has been demonstrated as being a mechanism for conserving the biodiversity, habitat connectivity and ecosystem service provision of brownfield sites following development $\left[17^{\bullet}, 2^{\bullet \bullet}\right]$

The Ready 4 Climate solution. This involves an inventory of extant information and information deficits to enable different knowledge-holders in municipalities to share knowledge across silos. New knowledge is derived by gaining insight into the departmental experience via a questionnaire and inventory (and information gaps) for different themes (i.e. heat stress, flooding). Combined, this gives a stress test based on which municipalities can decide whether or not it is urgent and/or useful to develop and implement a climate change adaptation strategy and if so, on which issues to focus. The process creates links experts within different departments, enabling further cooperation and integration between departments

The Green Living Room solution. This is another nature-based solution. It is a uniquely designed modular 3D urban green space for mitigating the negative effects of urbanisation such as heat stress. Besides micro-climatic benefits, this innovation enhances sojourn time quality, facilitates social activities, increases water retention capacity, reduces noise, absorbs pollutants and fine particulates, and supports for biodiversity. The multiple benefits to community well-being of this kind of strategic approach are beginning to be quantified $\left[9^{\bullet \bullet}, 30^{\circ *}\right]$. The Suburban Ecosystem Payments solution. This is a project implementing A payments for ecosystem services (PES) approach aimed at regulating sprawl. Developing PES programmes and projects has become topical in the past couple of decades; however, all such programmes and projects have been developed at national or international levels, but not at local levels where sprawl originates. The innovation of the Suburban Ecosystem Payments solution is in the employment of PES measures at that level and for the purpose of regulating sprawl [31"]. The proposed methodology of implementation comprising two main phases (initial definition of the payments and periodical updates) is innovative too: it overcomes the critical problems with the initial definition of PES charges by putting the emphasis on the second phase and developing a system for fine-tuning the levels of the charges over time

The Curatorial Planning solution. This is a transformation process that facilitates local authorities in supporting the type of collective system thinking that is needed for sustainable city-making. It draws on the notion of the 'curatorial' from art and design, and provides a practical approach to engage directly and constructively with complex problems evident with multi-scalar, multi-actor and multi-dimensional urban planning projects. It is implemented as a participatory workshop in which the facilitator (i.e. a local authorities or another bridging organisation) adopts the role of a curator

The Space Engagers solution. This is an online, self-generated tool for re-activating underused real estate assets in the urban core, in order to open them up for local engagement, ideas and projects. The crowd-sourced mapping of underused spaces can now become a core activity for strategic planning and can help address multiple socio-cultural and socio-economic challenges, as well as facilitate the transformation of social and ecological systems in the city. This innovation uses a variety of methods to collate data including existing datasets, community engagement in the field and crowd-sourcing volunteered, real-time data $\left[10^{\circ}\right.$ ] 


\begin{tabular}{ll} 
Table 1 (Continued) & \multicolumn{1}{c}{ Innovative solution example (including link) for building resilience } \\
\hline Process innovation & $\begin{array}{l}\text { The PSS toolkit solution. This solution combines different workshop methods based on system thinking and } \\
\text { participatory design to generate ideas of local business opportunities in form Product-Service Systems (PSS). } \\
\text { Designing a product under the conventional industrial paradigm in which the entrepreneur is the main (and often } \\
\text { only) actor differs radically from designing a PSS. This TURAS solution helps developing an understanding of } \\
\text { entrepreneurship as one part in a wider set of systemic interactions that include the community of users but also } \\
\text { engages the local public authorities. This integration is achieved by formulating the opportunities around urban } \\
\text { strategic sustainability challenges and by bringing the users' point of view in the process of examining the } \\
\text { system. The PSS toolkit goes further into testing the attractiveness and the feasibility of the business } \\
\text { opportunities whereas other workshop methods typically stop at the stage of idea development. It offers specific } \\
\text { steps for testing the new ideas formulated by confronting their most critical/sensitive aspects in realistic } \\
\text { simulations reflecting the system in which they would operate in the real world }\end{array}$ \\
\hline
\end{tabular}

innovation and a broader focus of the applications and varieties of innovation. In line with this policy, TURAS co-created numerous innovations, including nature-based solutions that 'organically' emerged from research and demonstration efforts $\left[9^{\bullet \bullet}, 10^{\bullet \bullet}\right]$. In short, the TURAS project narrowed the gap between transdisciplinary theory and practice [11], and has resulted in 85 innovative solutions to assist transitioning and ultimately transform how we continue as an urban species.

The focus on innovation has become a central policy platform for most academic and non-academic funders, but such a deliberate focus can act as a barrier to potential participants in research and demonstration projects, as well as those partners where capacity is diminished or not culturally or historically relevant. Therefore, to facilitate inclusion and cohesion, exploring some key aspects of innovation is important. To illustrate the global opportunities within current and future research funding offerings, this paper contains some of these alternative forms of innovation that have been derived, using transdisciplinary methodologies, within the TURAS project. As part of the research and demonstration process, this project produced numerous added-value innovations through the co-creation of ideas and knowledge by the interactions of academic institutions, local authorities and SMEs, in tandem with urban communities of interest. Figure 1 illustrates these interactions and the resulting innovations.

This figure is illustrative of the variety of transitioning solutions that can be co-created in a transdisciplinary, open innovation project and is in line with similar approaches $\left[12,13^{\bullet}, 14,15\right]$. These ideas also broadly align with differing typologies of innovation. Innovation in an urban sustainability context is seen as a form of resilience building, often as a reaction to sudden or episodic shock $\left[16,17^{\bullet}, 18,19\right]$. Though Snow [20] views innovation as integral to entrepreneurship, innovation can take many forms and is not solely linked to the development of a single product offering for the market: it is defined more broadly. Incremental innovation seeks to improve extant systems and processes based on expertise accumulated over time. Process innovation augments the delivery of these services to the community [21,22]. Sustainability innovation aims to embed ecological and environmental concerns within planning and policy processes [23], and knowledge innovation stimulates the production of new knowledge and how this may be conveyed. Business innovation looks at scaling-up ideas and solutions to a larger market, especially in the areas of eco-innovation [19]. Social innovation looks at meeting the needs of communities through a variety of outreach opportunities [24] such as governance innovation which seeks to embed collaborative processes in decision-making and city-making [8]. Open source innovation seeks new mechanisms for funding and exploiting these co-created ideas into planning practice [25]. The TURAS approach views these urban transformation strategies, and in the process a number of diverse innovations have emerged that broadly fit this list, as being essential for mainstreaming this complex methodology of co-designing research methods and co-producing knowledge. The result is a cluster of transformation strategies designed at drawing on innovation to build urban resilience and community cohesion [26 $6^{\circ}$. Table 1 takes these examples of innovations and applied them to the TURAS transitioning solutions, illustrating this with a cross section of those solutions that relate to differing transdisciplinary open innovations.

As some of the more striking outcomes of the TURAS project, the innovations this table illustrates can be viewed as pathways for planning and policy-making for mainstreaming transdisciplinarity in practice. This table serves as an illustration of the range and depth of mechanisms that all urban stakeholders can collaboratively develop, and as such could be a template for futureoriented transitioning and thus transform how city-making is realised in practice. Such collaborations can radically change policy outcomes and thus mainstream sustainability practices [32].

\section{Conclusions}

The conceptual premise for co-developing innovative strategies is an emerging novel and theoretical approach, but it can be argued that it is the most promising opportunity yet for transitioning within a diverse and complex environment. It is known that socio-political processes, 
cultural context, as well as a solid evidence base are integral to innovation policy creation [33]. Innovation can be seen as a reformation of existing and past knowledges in order to realize policies for the creation of the sustainable 'smart' city [34]. However, the examples shown here indicate a pathway for realising new kinds of transition strategies. Based on empirical research and learning-by-doing, these innovations have been realised using a transdisciplinary collaboration with all urban communities of interest; thus taking holistic governance processes from theory further towards integrated practice. This could provide a template for collaborative planning and adaptive governance for inclusive city-making and resilience-building. Each of the innovations in the TURAS project has been derived using iterative transdisciplinary processes, an approach which has emerged as a powerful tool for building resilience [35], but it is too soon to say that transdisciplinarity is a panacea and while co-creation and co-design form the backbone of sustainability policy at this time, more empirical evidence and analysis of results are needed. The co-creation and codesign can be slow, relatively expensive and often requires additional and specialised skill sets. Transdisciplinarity has a limited appeal to planners and policymakers who may be under more urgent pressure to address the complex issues of climate adaptation, wellbeing, employment, migration and other heavily politicised and divisive urban issues. However, the transdisciplinary process has proven cohesion and innovation benefits that can reach beyond limitations, and the TURAS project is a step change example of the kinds of processes and strategies that illuminate pathways to more inclusive, resilient city-making. Collaborative projects like TURAS, with the resulting innovations derived through transdisciplinary processes, can provide veracity and robustness to theories of transdisciplinarity and transitioning, and serve to bring urban society closer to the end goal of complete and sustainable transformation.

\section{Acknowledgements}

The authors acknowledge the financial support by the European Union FP7-ENV.2011.2.1.5-1 (TURAS Project) Grant Agreement no. 282834. This section will be completed after the review process.

\section{References and recommended reading}

Papers of particular interest, published within the period of review, have been highlighted as:

- of special interest

•• of outstanding interest

1. Voorberg WH, Bekkers VJJM, Tummers LG: A systematic review

- of co-creation and co-production: embarking on the social innovation journey. Public Manage. Rev. 2015, 17:1333-1357.

This is an excellent review of the co-creation process and outlines many of the benefits and disbenefits of co-creation.

2. Homsy GC, Warner ME: Cities and sustainability: polycentric action and multilevel governance. Urban Aff. Rev. 2014, 51:46-73.

3. Brandt P, Ernst A, Gralla F, Luederitz C, Lang DJ, Newig J, Reinert F, Abson DJ, von Wehrden $\mathrm{H}$ : A review of transdisciplinary research in sustainability science. Ecol. Econ. 2013, 92:1-15.

4. Lang DJ, Wiek A, Bergmann M, Stauffacher M, Martens P, Moll P, Swilling M, Thomas CJ: Transdisciplinary research in sustainability science: practice, principles, and challenges. Sustain. Sci. 2012, 7:25-43.

5. Jahn T, Bergmann M, Keil F: Transdisciplinarity: between - mainstreaming and marginalization. Ecol. Econ. 2012, 79:1-10. This is a critique of transdisciplinarity.

6. EC (European Commission): The Open Innovation 2.0 Yearbook 2015. Luxembourg: European Commission; 2015, 114.

This is a full description of the design of open innovation and the transdisciplinary approach to innovation creation.

7. Kaasinen E, Koskela-Huotari K, Ikonen V, Niemelä M, Näkki P: Three approaches to co-creating services with users. In Advances in the Human Side of Service Engineering, vol. 286. Edited by Spohrer JC, Freund LE . CRC Press; 2013.

8. Swyngedouw E: Governance innovation and the citizen: the Janus face of governance-beyond-the-state. Urban Stud. 2005, 42:1991-2006.

9. Connop S, Vandergert P, Eisenberg B, Collier MJ, Nash C,

- Clough J, Newport D: Renaturing cities using a regionallyfocused biodiversity-led multifunctional benefits approach to urban green infrastructure. Environ. Sci. Policy 2016, 62:99-111.

This is a key paper on how a biodiversity led co-creational demonstrative approach can be used to unlock Sutainability and Business innovation in Nature Based Solution delivery in urban areas. The paper details three case studies from the TURAS project on how this can be achieved: ecomimicry at Barking Riverside; the Green Living Room in Ludwigsburg; Derbyshire St. Pocket Park in Tower Hamlets.

10. Crowe PR, Foley K, Collier MJ: Operationalizing urban resilience

-• through a framework for adaptive co-management and design: five experiments in urban planning practice and policy Environ. Sci. Policy 2016, 62:112-119.

This is an outline of how adaptive co-management in an urban setting can be realised and valuidated.

11. Zscheischler J, Rogga S: Transdisciplinarity in land use science-a review of concepts, empirical findings and current practices. Futures 2015, 65:28-44.

12. Muñoz-Erickson TA: Co-production of knowledge-action systems in urban sustainable governance: the KASA approach. Environ. Sci. Policy 2014, 37:182-191.

13. Frantzeskaki N, Kabisch N: Designing a knowledge co-• production operating space for urban environmental governance lessons from Rotterdam, Netherlands and Berlin, Germany. Environ. Sci. Policy 2016.

This paper presents a better picture of the process of co-creation and codesign as appliect in an urban setting.

14. Polk M: Transdisciplinary co-production: designing and testing a transdisciplinary research framework for societal problem solving. Futures 2015, 65:110-122.

15. König A: Towards systemic change: on the co-creation and evaluation of a study programme in transformative sustainability science with stakeholders in Luxembourg. Curr. Opin. Environ. Sustain. 2015, 16:89-98.

16. Lazzeretti L, Capone F: Innovations and innovators in a resilient city: the case of chemical innovations after the 1966 flood in Florence City. Cult. Soc. 2015, 6:83-91.

17. Ahern J, Cilliers S, Niemelä J: The concept of ecosystem

- $\quad$ services in adaptive urban planning and design: a framework for supporting innovation. Landsc. Urban Plann. 2014, 125:254259.

This is a keystone paper promoting a "learning-by-doing" participatory approach for unlocking urban ecosystem services delivery for resilient urban design.

18. Leach M, Rockström J, Raskin P, Scoones I, Stirling AC, Smith A, Thompson J, Millstone E, Ely A, Arond E et al.: Transforming innovation for sustainability. Ecol. Soc. 2012, 17.

19. Han J, Fontanos P, Fukushi K, Herath S, Heeren N, Naso V, Cecchi C, Edwards P, Takeuchi K: Innovation for sustainability: 
toward a sustainable urban future in industrialized cities. Sustain. Sci. 2012, 7:91-100.

20. Snow CC: Innovation. Strateg. Entrepreneur. J. 2007, 1:101-102.

21. Davenport TH: Process Innovation: Reengineering Work Through Information Technology. Harvard Business Press; 2013

22. Duranton G, Puga D: Nursery cities: urban diversity, process innovation, and the life cycle of products. Am. Econ. Rev. 2001, 91:1454-1477.

23. Schaltegger S, Wagner M: Sustainable entrepreneurship and sustainability innovation: categories and interactions. Bus. Strategy Environ. 2011, 20:222-237.

24. Nicholls A, Murdock A: The nature of social innovation. In Social Innovation: Blurring Boundaries to Reconfigure Markets. Edited by Nicholls A, Murdock A. UK: Palgrave Macmillan; 2012:1-30.

25. Seltzer E, Mahmoudi D: Citizen participation, open innovation, and crowdsourcing: challenges and opportunities for planning. J. Plann. Lit. 2012, 28:3-18.

26. Collier MJ, Nedović-Budić Z, Aerts J, Connop S, Foley D, Foley K,

- Newport D, McQuaid S, Slaev A, Verburg P: Transitioning to resilience and sustainability in urban communities. Cities 2013 32:S21-S28.

This paper was the precursory theory paper establishing the stratgey for co-creation and co-delivery of TURAS partnerships to effect multi-stakeholder engagement in local demonstrable transitioning initiatives.

27. Vandergert P, Sandland S, Newport D, van den Abeele P: Harnessing advances in eco-innovation to achieve resource efficient cities. In Green Design, Materials and Manufacturing Processes. Edited by Bartolo H, Bartolo PJDS, Alves NMF, Mateus AJ, Almeida HA, Lemos ACS, Craveiro F, Ramos C, Reis I, Durão L. et al.: CRC Press; 2013:755-760.

28. de Moel H, Jongman B, Kreibich H, Merz B, Penning-Rowsell E, Ward PJ: Flood risk assessments at different spatial scales. Mitig. Adapt. Strateg. Glob. Change 2015, 20:865-890.
29. Connop S, Nash C: Ecomimicry for Barking Riverside: Achieving -• Locally Contextualised Biodiversity-led Multifunctional Urban Green Infrastructure. Project Report. London: University of East London; 2016.

This report is an example output from collaborative Sustainable Innovation within the TURAS project. The report details ecomimicry design guidelines for developers, architects and landscape architects at a large development project in the case study city of London, UK. Guidelines are based on co-created nature based solution experiments and case studies at the site.

30. Krekel C, Kolbe J, Wüstemann H: The greener, the happier? The - effect of urban land use on residential well-being. Ecol. Econ. 2016, 121:117-127.

This is a step-change paper demonstrating a method to move from qualification to quantification of links between urban greenspace landuse and residential well-being.

31. Bolund $P$, Hunhammar S: Ecosystem services in urban areas - Ecol. Econ 1999, 29:293-301.

This is one of the formative foundation publications raising awareness of the critical role of ecosystem provision in urban sustainability. It is widely cited as an exemplar of ecosystem service understanding.

32. Frantzeskaki N, Kabisch N: Designing a knowledge coproduction operating space for urban environmental governance-lessons from Rotterdam, Netherlands and Berlin, Germany. Environ. Sci. Policy 2016, 62:90-98.

33. Borrás S, Edquist C: Education, training and skills in innovation policy. Sci. Public Policy 2014, 42:215-227.

34. Viñals CR: Introduction to social innovation as a new form of organisation in knowledge-based societies. In Social Innovation: New Forms of Organisation in Knowledge-Based Societies. Edited by Viñals CR, Rodríguez CP. Routledge; 2013: 3-11.

35. Mauser W, Klepper G, Rice M, Schmalzbauer BS, Hackmann H, Leemans $\mathrm{R}$, Moore $\mathrm{H}$ : Transdisciplinary global change research: the co-creation of knowledge for sustainability. Curr. Opin. Environ. Sustain. 2013, 5:420-431. 